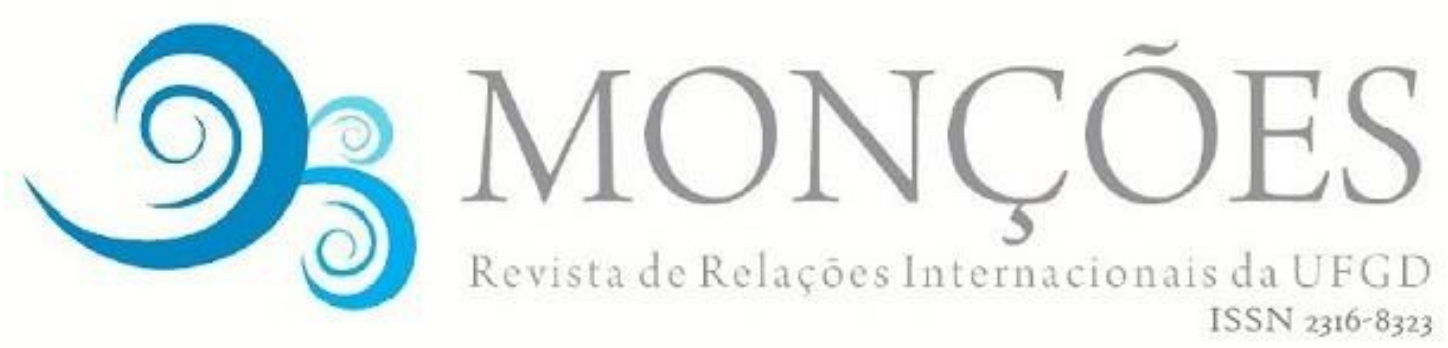

\title{
AS AGÊNCIAS DE CLASSIFICAÇÃO DE RISCO E SEUS IMPACTOS SOBRE A GOVERNANÇA DEMOCRÁTICA: UMA ANÁLISE DO CASO BRASILEIRO
}

\author{
PEDRO LANGE NETTO MACHADO \\ Mestrando em Relações Internacionais pela Universidade Federal de Santa Catarina \\ (UFSC) e bolsista CAPES.
}

\begin{abstract}
RESUMO: Este artigo argumenta que as agências de classificação de risco atuam como um canal de pressão por meio do qual as preferências políticas do mercado financeiro se impõem aos Estados nacionais. No contexto de globalização financeira, os governos se veem em meio ao conflito entre as demandas democráticas de seus eleitores e as pressões provenientes do sistema internacional de finanças. Um dos instrumentos que materializam essas pressões são as agências de classificação de risco, que confrontam o sistema político vigente nos Estados e, por consequência, a governança democrática. O argumento se desenvolve a partir do caso do Brasil, desde o processo de impeachment de Dilma Rousseff até a suspensão da votação da reforma da previdência pelo governo Temer, e se confirma a partir da análise de relatórios e dos ratings emitidos pelas agências, assim como de suas declarações nos canais de mídia.
\end{abstract}

PALAVRAS-CHAVE: Globalização financeira; agências de classificação de risco; Brasil.

\section{CREDIT RATING AGENCIES AND THEIR IMPACTS ON DEMOCRATIC GOVERNANCE: AN ANALYSIS BASED ON THE BRAZILIAN CASE}

\begin{abstract}
This article argues that credit rating agencies act as a pressure channel through which financial market political preferences are imposed on national states. In a context of financial globalization, governments find themselves amidst the conflict between the democratic demands of their constituents and the pressures from the international financial system. One of the instruments that materialize these pressures are the credit rating agencies, which confront the national political systems and, as a consequence, the democratic governance. The argument develops from the Brazilian case, from the impeachment process of Dilma Rousseff to the suspension of the vote on the social insurance reform by the government of Michel Temer, and is confirmed through the analysis of reports and the ratings issued by the agencies, as well as of their statements on the media channels.
\end{abstract}

KEYWORDS: Financial globalization; credit rating agencies; Brazil 


\section{Introdução}

O mundo de mercados globalizados, que emerge nas últimas décadas do século $X X$, testemunha os frequentes atritos entre capitalismo e governos democráticos. A globalização, em especial em sua manifestação financeira, incide sobre a margem de manobra de governos nacionais, que se encontram em meio ao conflito entre as demandas populares de seus eleitores e as pressões provenientes do mercado financeiro. É nesse contexto que as agências de classificação de risco adquirem relevância, uma vez que delas depende, em grande parte, as condições de acesso dos Estados ao mercado de capitais. Nesse sentido, este artigo argumenta que essas agências atuam como um canal de pressão por meio do qual as preferências de política econômica da finança globalizada se impõem aos Estados nacionais. Essas pressões, como será analisado, se materializam de formas variadas, constrangendo e lesando a governança democrática dos países sobre os quais incidem.

Essa realidade se manifesta com maior clareza diante da análise do caso do Brasil, sobretudo a partir do cenário que se observa durante e após o impeachment da presidente Dilma Rousseff, do Partido dos Trabalhadores (PT). Nesse contexto, o ativismo das agências de classificação de risco explicita o viés político de suas atuações, configurando-se como uma amostra do poder das finanças face a um país confrontado por uma crise política e econômica. Como se evidenciará a partir da análise de seus relatórios e manifestações midiáticas, além da própria classificação do país pelas agências, a interferência desses atores no jogo político e democrático de qualquer país não pode ser ignorada diante da necessidade de se melhor compreender a realidade em que vivemos e para que se possa, assim, vislumbrar melhores perspectivas de governança global.

$\mathrm{O}$ argumento proposto se desenvolve em três etapas, a partir das quais este trabalho está organizado. Desse modo, a primeira seção analisa elementos da relação entre a globalização financeira e os governos nacionais por ela condicionados. Tal reflexão lança as bases para a discussão da seção seguinte, acerca das agências de classificação de risco e das principais polêmicas e controvérsias em torno de suas atividades. Finalmente, a terceira seção apresenta aspectos da relação entre o Brasil e essas agências que permitem verificar o 
argumento trabalhado, viabilizando a identificação de questões levantadas em nível teórico pela literatura especializada.

\section{Globalização financeira e governança democrática}

No século XXI, a democracia se consolida como substrato de um Estado idealizado, cujos canais de diálogo com sua população seria a condição que viabilizaria a promoção do desenvolvimento humano ${ }^{1}$ (EVANS, 2010). Essa percepção se dá na esteira da falha das instituições neoliberais, predominantes no último quartel do século passado, em cumprir com esse objetivo. Não obstante, o processo de globalização, em suas variadas expressões, que se configurou e se estabeleceu ao longo desse mesmo período, impõe hoje uma série de desafios à governança democrática, que podem minar a base dessa ascendente lógica desenvolvimentista. Conforme apontado na introdução deste artigo, esta seção visa a apresentá-los a partir do processo que se convenciona chamar de globalização financeira.

A percepção das incompatibilidades entre democracia e capitalismo é, no entanto, anterior ao advento dessa vertente da globalização. Belluzzo (2018), por exemplo, observa que os próprios teóricos do pensamento liberal - como Locke, Mandeville, Burke e Hayek ${ }^{2}$ - já manifestavam preocupações acerca dos possíveis danos causados ao mercado pelo estabelecimento de governos democráticos. Streeck (2012), por sua vez, percebe que esse embate de forças conflitantes se materializa de formas variadas ao longo da história ${ }^{3}$, mas está sempre enraizado na convivência entre dois princípios de alocação inconciliáveis: um que opera em função das leis do mercado, pautado por uma lógica de produtividade marginal, e outro fundamentado em políticas democráticas em prol de necessidades e de

\footnotetext{
${ }^{1}$ A agenda de pesquisa proposta por Evans (2010) parte do conceito de desenvolvimento proposto por Sen (2000), pautado na expansão de capacitações humanas.

${ }^{2}$ Para Hayek, por exemplo, "há um conflito irreconciliável entre democracia e capitalismo [...]. Agora, tornou-se indiscutível que os poderes da maioria são ilimitados e que governos com poderes ilimitados devem servir às maiorias e aos interesses especiais de grupos econômicos" (HAYEK apud BELLUZZO, 2018)

${ }^{3}$ Algumas dessas manifestações seriam a alta inflação a partir da década de 1970, seguida pelo recurso ao endividamento público e, posteriormente, ao endividamento privado.
} 
direitos sociais. Já Rodrik (2011) aponta para a inviabilidade da coexistência entre mercados globalizados e democracia estatal, uma vez que as forças da globalização e os arranjos sociais domésticos seriam essencialmente conflitivos, o que tornaria inevitável a necessidade de flexibilização ou de sacrifício de uma das duas condições.

É a partir do final da década de 1970, contudo, que esse conflito é potencializado pelo que Chesnais $(1996,2010)$ denominou como um golpe de Estado financeiro - que viria a desencadear os processos que operacionalizaram o que ficou conhecido por globalização financeira. Esse conjunto de mudanças na organização internacional de finanças - enraizadas em decisões políticas dos governos de Reagan e de Tatcher - fez com que o capitalismo ingressasse em um novo regime mundial de acumulação, pautado pela financeirização da riqueza. $\mathrm{Na}$ lógica que se estabelecia, à progressiva desregulamentação ${ }^{4}$ e interpenetração dos mercados de capitais, somaram-se os processos de desintermediação financeira e de securitização, que, junto a outras condições ${ }^{5}$, viabilizaram o que o autor descreve como mundialização do capital. Essa nova realidade passou a permitir que os governos nacionais procedessem à securitização dos ativos de suas dívidas públicas, de modo a obter, nos mercados financeiros, o financiamento para seus déficits orçamentários (ibidem).

Não obstante, Chesnais (1995) também observa que a configuração desse sistema financeiro internacional passaria, a partir de então, a promover mudanças qualitativas nas relações entre os Estados e o capital, uma vez que suas economias ficariam à mercê da liberdade de que este passou a gozar para se deslocar de um país para o outro. Ao analisar essa perda de poder relativo dos Estados frente aos mercados, Strange (1994), identifica, contudo, uma autoridade nacional como portadora de um poder estrutural ${ }^{6}$, dentro do qual essa arquitetura financeira se

\footnotetext{
${ }^{4}$ Para Lima (1997), contudo, tal processo seria melhor descrito como uma nova regulamentação em favor da livre movimentação de capitais, uma vez que o termo "desregulamentação" sugere uma ausência de normas nesse âmbito, o que não é a realidade.

${ }^{5}$ Chesnais (1996) destaca também, por exemplo, os avanços tecnológicos na indústria telemática, assim como a reorganização espacial das cadeias de produção, em conformidade com a conveniência financeira das corporações.

${ }^{6}$ Strange (1994) define o poder estrutural como o poder para moldar e determinar as estruturas da economia política global dentro das quais outros Estados - e suas instituições, empresas e cidadãos - operam. Trata-se de uma noção que visava à contestação das teses acerca do declínio 
estabelece: os Estados Unidos. Com efeito, ainda que mesmo o governo americano tenha se enfraquecido frente ao dos mercados, é dentro de estruturas de poder emanadas dos Estados Unidos que o sistema internacional de finanças passa a operar (STRANGE, 1994, 1996). Ademais, é a partir dessa lógica que o processo de globalização financeira pode ser entendido nos termos de uma expansão do sistema financeiro estadunidense para outros países, que abrem seus espaços socioeconômicos para que sejam estruturados conforme regras e práticas de origem norte-americanas. Internacionalmente, essa realidade se traduziu nos preceitos do Consenso de Washington, que passaram a ser propagados pelas instituições financeiras que operam nesse contexto (KONINGS \& PANITCH, 2009).

Ainda que as origens e os propósitos do processo de globalização financeira encontrem respostas diferentes em distintas perspectivas teóricas, os efeitos dele provenientes acabam por convergir para a maior parte dos Estados nacionais. Nesse sentido, para os países inseridos na estrutura que se construiu, uma das consequências é o permanente risco de fuga de capitais - e, consequentemente, de uma crise no balanço de pagamentos - no caso de perda da confiança do mercado financeiro. É essa constante ameaça que faz com que seus governos se vejam obrigados a respeitar a "disciplina do mercado", ainda que, por vezes, em detrimento dos interesses de seus próprios eleitores. Nesse contexto, Eichengreen (2000) percebe a mobilidade de capitais como uma salvaguarda para os credores diante dos inconvenientes da democracia - no caso de políticas contrárias aos seus interesses, bastaria deslocar seus investimentos para um país mais adequado. Assim, diante dessa situação de permanente ameaça de crise financeira, as políticas estatais, que supostamente deveriam se voltar às necessidades dos cidadãos de seus países, acabam frequentemente por privilegiar as demandas do mercado financeiro (CARVALHO, 2004; DOWBOR, 2017).

hegemônico dos Estados Unidos, que, no último quartel do século $\mathrm{XX}$, teria sofrido uma perda de poder relacional, ao passo em que, em contrapartida, passava a desfrutar de um maior poder estrutural.

${ }^{7}$ Carvalho (2004) critica o substrato ideológico da globalização financeira, que se fundamentaria em abstrações acerca de uma melhor alocação internacional de capitais, beneficiando, supostamente, países emergentes - onde se supõe que haja mais oportunidades de investimentos e o capital seja menos abundante. Na realidade, contudo, o que se observa é que essas economias viram reféns do humor de investidores e passam a conviver com um permanente risco de uma fuga de capitais. 
Mais dependentes do capital externo para financiar suas dívidas públicas, os países emergentes são os que, consequentemente, sofrem maiores constrangimentos no contexto da finança globalizada. De fato, esses países padecem de um controle mais rígido por parte do mercado financeiro, que reage não apenas a seus indicadores macroeconômicos, mas também a políticas microeconômicas - que poderiam impactar na capacidade de pagamento de suas dívidas - e, até mesmo, à ideologia político-partidária de seus governos (MOSLEY, 2003). Campello (2015) observa, no entanto, que o grau de pressão exercido pelas finanças varia conforme ciclos de abundância e escassez de capitais, que, desse modo, se tornam um fator exógeno relevante para a condução política e econômica em países emergentes. Nesse sentido, tais pressões recairiam em especial sobre governos de esquerda, que, em cenários desfavoráveis, se veriam constrangidos a se distanciar de suas agendas originais para conquistar a confiança do mercado. Entretanto, o que se verifica é que, independentemente da conjuntura, o mercado financeiro, mediante seu poder de deslocar capitais e impor altas taxas de juros ao financiamento desses países, mantém conservada sua capacidade de influenciar diretamente em seus cenários político e econômico (CAMPELLO, 2015).

Os meios pelos quais o poder das finanças é exercido sobre os Estados são variados e se refletem na captura dos sistemas políticos que poderiam representar um contrapeso à sua ação, o que acaba por restringir o território ocupado pela política democrática (DOWBOR, 2017). Nessa rede de poder pela qual as finanças operam, pressionando governos e deformando democracias, as agências de rating, diante de sua natureza privada e de sua ação pretensamente técnica, passam comumente despercebidas nas análises da literatura sobre o tema. $O$ foco da seção subsequente recai, assim, sobre esse particular canal de manifestação do sistema financeiro internacional.

\section{As agências de classificação de risco}

Também conhecidas como agências de rating, as agências de classificação de risco são empresas privadas e independentes, especializadas na avaliação de crédito a partir de instrumentos de emissão de dívida. A classificação de risco 
oferecida por essas agências pode se aplicar a empresas de diferentes naturezas ou a governos, nacionais ou subnacionais. Em conformidade com a finalidade deste trabalho, apenas o rating soberano, referente a Estados soberanos, será considerado na análise que se segue. Nesse sentido, o Tesouro Nacional (2018) o define como "uma avaliação da capacidade e da disposição de um país em honrar, pontual e integralmente, os pagamentos de sua dívida" em conformidade com o pactuado com os credores.

Atualmente, o segmento de classificação mundial de risco soberano se encontra monopolizado por três agências: Standard \& Poor's, Moody's - que juntas detêm $85 \%$ desse mercado - e, em menor grau, Fitch Ratings. Por conseguinte, são a estas empresas que este trabalho se refere quando se fala sobre agências de rating ou de avaliações delas provenientes. Ainda que suas origens remontem ao final do século $X I X^{8}$, é somente a partir da década de 1970, com a globalização financeira e a consequente expansão dos mercados de capitais, que essas empresas adquirem a relevância e a influência de que hoje desfrutam. A explicação para isso, conforme já apontado, está no movimento de desintermediação financeira e de desregulamentação do sistema financeiro internacional, que gerou uma lacuna, para os credores, relativa ao acesso a informações acerca dos riscos de seus investimentos - função esta outrora desempenhada pelos bancos, que anteriormente intermediavam esse processo (SINCLAIR, 2005).

Esse vácuo informacional passa a ser, assim, preenchido pelas agências de classificação de risco. Como, com a globalização financeira, gradativamente os mercados de capitais foram se tornando a fonte mais atrativa para o financiamento de dívidas públicas (CAMPELLO, 2015), o rating soberano se torna, nesse contexto, um referencial orientador para alocação internacional de fundos, passando a funcionar, conforme observado por Ywata (2012), como uma espécie de bússola para o capital financeiro. Sua formulação, em meio a essa realidade, ocorre mediante a atribuição de notas, que assumem a forma de conceitos, aos países que são objetos da avaliação. Nesse processo, uma série de variáveis quantitativas e

\footnotetext{
${ }^{8} \mathrm{Na}$ década de 1890, a empresa predecessora da Standard \& Poor's já publicava manuais de análise de títulos, ao passo que John Moody inauguraria a indústria de classificação de risco na primeira década do século XX (PARTNOY, 2005).
} 
qualitativas - como, por exemplo, nível de endividamento público em relação ao PIB, condução das políticas fiscal e monetária e ambiente sociopolítico - são levadas em conta e originam o conceito representativo do rating soberano ${ }^{9}$.

Uma vez divulgada, essa nota passa a influenciar a decisão de investidores no sistema financeiro internacional, que atuam no sentido de maximizar seus lucros e de minimizar os riscos de seus investimentos. Desse modo, quanto pior a nota obtida por um Estado, mais caro se torna o financiamento de sua dívida, o que reflete a influência e 0 impacto da opinião ${ }^{10}$ concedida por essas agências no balanço de pagamentos de um país e, consequentemente, na vida de todos os seus cidadãos. Com efeito, essa influência é ainda potencializada pela condição de que essas empresas desfrutam como Organizações Nacionalmente Reconhecidas de Estatísticas de Rating ${ }^{11}$ - conforme o Acordo da Basileia II -, que atrela legalmente a ação de fundos de investimento diversos às suas opiniões (PARTNOY, 2006).

Tal influência, contudo, não é exercida apenas a partir da emissão do rating - que por si só já refletiria o poder que detêm essas agências, uma vez que esse indicador impacta diretamente no acesso de um país ao mercado de capitais -, mas também por meio de manifestações midiáticas e de relatórios que apresentam prescrições de políticas a serem adotadas para que, supostamente, se possa ascender na classificação. Essas orientações, por sua vez, estão sempre em consonância com as práticas recomendadas pelo Consenso de Washington e se pautam por um modelo neoliberal de organização econômica (KUNDU, 2001; SINCLAIR, 2005; YWATA, 2012; PAUDYN, 2014). O estabelecimento e o uso coordenado desses diferentes canais de pressão fazem, por conseguinte, com que governos nacionais sejam constrangidos a adotar as tão propagadas políticas de austeridade econômica, que, ainda que agradem ao mercado, nem sempre apresentam o resultado desejado em termos de recuperação econômica (IOANNOU, 2016; LUTEN, 2016).

\footnotetext{
${ }^{9}$ As três agências consideradas neste trabalho disponibilizam em suas páginas na internet a metodologia e as variáveis levadas em conta no cálculo do rating.

${ }^{10}$ São as próprias agências que se apresentam, em seus relatórios e em suas páginas online, como tão somente portadoras de uma opinião.

${ }^{11}$ Tradução de Nationally Recognized Statistical Rating Organizations.
} 
Diante dessas diferentes vias de atuação, a literatura vem observando uma série de falhas e de controvérsias em torno da atividade das agências de classificação de risco.

Nesse sentido, um foco constante de críticas é o próprio processo de elaboração do rating, o que leva a questionamentos acerca do real propósito dessas empresas. Para Sinclair (2005), por exemplo, ainda que se apresentem como técnicas e neutras, as agências de rating são entidades eminentemente políticas, em cujos julgamentos está implícita uma visão de mundo voltada aos interesses dos investidores - à qual o autor se refere como "ortodoxia do rating". Essa ortodoxia, por sua vez, seria o vetor de um modelo de organização capitalista anglo-saxônico, o que condiz com o próprio locus de origem das maiores agências de classificação de risco - cujas sedes se situam em Nova lorque - e com a noção de globalização financeira apresentada na seção anterior.

Dentro dessa lógica, a atividade das agências não se basearia tanto na solidez das informações que proporcionam, mas sim na autoridade intelectual que adquirem - dados os impactos que possuem suas avaliações e declarações - e na consequente influência que exercem sobre a configuração de normas e de políticas adotadas pelos Estados. Uma das principais funções dessas empresas seria, assim, a de um canal transmissor de políticas e normas neoliberais, que visam à sincronização e à convergência institucional dos Estados, em especial os de economia emergente, reféns do financiamento nos mercados de capitais. Trata-se da mesma visão adotada na análise de Kundu (2001), que percebe o rating como instrumento de persuasão que faz com que governos sigam a agenda do mercado financeiro, pautada pela disciplina fiscal, em detrimento de seus próprios interesses.

Paudyn (2014) se coaduna com essas perspectivas, destacando esse mesmo alinhamento das agências de rating com os preceitos neoliberais de organização econômica. Para o autor, a quantificação do risco - forjada a partir de uma série de inconsistências, uma vez que diversas variáveis qualitativas são, inadequadamente, mensuradas numericamente - serviria ao propósito de despolitizar a soberania fiscal e a governança orçamentária dos Estados, promovendo uma bifurcação artificial entre política e economia domésticas. Dentro 
dessa lógica, o caráter científico e técnico com que se travestem suas avaliações, que reverbera e adquire autoridade discursivamente, ajuda a dotar o programa neoliberal de materialidade e longevidade, blindando aspectos de política econômica do debate político. O rating, por conseguinte, tornar-se-ia uma ferramenta de controle e de governança.

As ideias de Paudyn (2014) são também respaldadas pela análise mais ampla feita por Le Galès (2016) acerca dos indicadores de performance - dentre os quais está o rating - e o papel disciplinador que exercem hoje sobre os Estados. A teoria desse autor parte da percepção de que tais índices não são politicamente neutros e que constituem uma modalidade de exercício de poder que pode ser revelador sobre as estruturas de dominação existentes em uma sociedade. Desse modo, esses indicadores seriam instrumentalizados politicamente em prol do fomento à competição, à qual os Estados devem se adaptar ou arcar com as sanções correspondentes.

A problematização da natureza do rating, assim como do real papel desempenhado pelas agências de classificação de risco, oferece esclarecimentos acerca das inconsistências de suas ações empiricamente observadas pela literatura. Tendo em mente essa essência parcial e política, pode-se melhor compreender o comportamento das agências ao discriminarem governos de esquerda, atribuindo a seus países avaliações piores simplesmente em decorrência da ideologia partidária de seus governos - o que é observável tanto em países emergentes (BLOCK \& VAALER, 2004; VAALER SCHRAGE \& BLOCK, 2006) quanto nos de economia já desenvolvida (BARTA \& JOHNSTON, 2017). Ademais, como são os próprios governos que contratam seus avaliadores, também vêm sendo observados atrasos na divulgação de downgrades em anos eleitorais, o que, logicamente, beneficia os candidatos da situação - ou seja, seus contratantes (BUENFIL, 2017). Por sinal, o conflito de interesses decorrente do fato de as agências serem pagas pelos próprios emissores de dívida se torna ainda mais evidente em uma realidade de competição por clientes, o que permite que estes contratem os serviços que Ihes forem mais convenientes - optando, assim, pela empresa que oferecer a melhor avaliação (BOLTON, FREIXAS \& SHAPIRO, 2011). 
Uma vez esclarecido esse modus operandi, torna-se também menos surpreendente que essas agências, afinal, não confiram tanta importância - como, dada a natureza do produto que oferecem, seria de se esperar - às suas respectivas reputações como avaliadoras de risco (MATHIS, MCANDREWS \& ROCHET, 2009), o que agrava preocupações em torno de eventuais conflitos de interesses que possam levar a distorções ainda maiores nos ratings que emitem. Com efeito, Dowbor (2017) denuncia a efetiva negociação de melhores avaliações por dinheiro, o que estaria associado à má regulamentação dessas atividades, assim como à recorrente impunidade registrada em casos suspeitos ${ }^{12}$. A justiça estadunidense, aliás, diante de erros de grandes proporções cometidos pelas agências, vem aceitando seus argumentos de que o que fazem é tão somente emitir uma opinião, o que estaria, assim, respaldado constitucionalmente, mas que ignora as consequências de suas ações e a posição por elas ocupadas no movimento internacional de finanças (PARTNOY, 2006).

Finalmente, o que se pode inferir a partir do panorama apresentado é que as agências de classificação de risco são entidades mais politizadas e menos científicas do que a forma como se apresentam e a função que desempenham no sistema financeiro internacional deixariam transparecer. Uma vez que as economias emergentes se encontram em posição de maior vulnerabilidade frente à globalização financeira, é de se esperar que sejam esses os países que se vejam mais constrangidos e pressionados pela ação das agências de rating, que restringem e influenciam mais acentuadamente as escolhas políticas de seus governos. Nesse sentido, o caso do Brasil torna-se representativo desse tipo de ingerência externa em temas de política nacional e de governança democrática. Em especial, a partir das crises política e econômica que culminaram no impeachment de Dilma Rousseff, algumas das manifestações que tanto debate suscitam na literatura emergem com maior clareza, como será analisado a seguir.

\footnotetext{
12 Dowbor (2017) lembra que, mesmo após os erros cometidos pelas agências de rating, que em muito contribuíram para a escalada da crise financeira global desencadeada em 2008, ninguém foi preso nem teve de assumir a culpa: a Moody's, condenada, precisou pagar 864 milhões de dólares, enquanto a Standard \& Poor's já pagou mais de 1 bilhão de dólares.
} 


\section{0 caso do Brasil}

Entre 2 de dezembro de 2015 e 31 de agosto de 2016, o processo de impeachment da presidente Dilma Rousseff, do PT, se desenvolveu e foi concluído com a ascensão de seu vice-presidente, Michel Temer, do PMDB, à presidência da república. A análise que se propõe visa a contemplar o período que se estende desde o início desse processo até os primeiros meses de 2018, uma vez que nesse espaço temporal se pode identificar com maior clareza, conforme sinalizado, algumas interferências das principais agências de classificação de risco no jogo político brasileiro. Não é o objetivo desta análise esgotar todos os elementos que apontem nesse sentido, mas apenas identificar e problematizar alguns deles, para, a partir da literatura apresentada, sustentar o argumento de que as agências de rating atuam como um canal de interferência da globalização financeira na esfera política e democrática do país.

Ao longo da década de 1990, o Brasil firmou contrato com as três principais agências levadas em consideração neste trabalho - Standard \& Poor's, Moody's e Fitch Ratings ${ }^{13}$. Desde então, alguns exemplos de distorções no rating do país, que exemplificam o que posteriormente seria explorado com maior clareza pela literatura, podem ser identificados. Em 2002, por exemplo, às vésperas da eleição de Lula da Silva, proveniente do PT, à presidência da república, tanto a Moody's quanto a Fitch Ratings rebaixaram a classificação do país devido às incertezas em torno do então candidato da esquerda que despontava com grandes chances de vencer o pleito - 0 que ilustra a já apontada discriminação contra partidos de esquerda por parte das agências. Na ocasião, o protesto do Ministério da Fazenda e do Banco Central já apontava as inconsistências em torno da queda do rating, em nota noticiada pela Folha de S. Paulo em outubro daquele ano:

A própria agência, em nota divulgada na manhã de hoje, reconhece sua incapacidade de formar um juízo a respeito da matéria. No entanto, age como se soubesse que o próximo governo não será capaz de lidar de forma adequada com a questão, embora elogie sinais emitidos pelo candidato que lidera as pesquisas. [...] Ao não fornecer qualquer razão técnica para sustentar a sua tese, a agência transforma sua decisão em um exercício de

\footnotetext{
${ }^{13}$ O Tesouro Nacional (2018) esclarece, em sua página na internet, que o Brasil também é avaliado regularmente por outras empresas: a canadense Dominion Bond Rating Service (DBRS), as japonesas Japan Credit Rating Agency (JCR) e Rating and Investment Information (R\&I), a coreana NICE Investors Service a a chinesa Dagong Global Credit Rating.
} 
especulação sobre o curso futuro dos eventos, exercício que poderia ser aplicado a qualquer país, levando ao mesmo tipo de conclusões equivocadas.

Posteriormente, contudo, o governo de Lula da Silva viria a conquistar a confiança do mercado financeiro, o que se refletiria na elevação do rating soberano brasileiro aos maiores níveis de sua história ${ }^{14}$. Essa tendência, não obstante, passa a se inverter ao longo de 2014, enquanto, já nos anos subsequentes, o rating nacional enfrentaria uma série de rebaixamentos. Diante desse contexto, a tabela a seguir contempla as quedas na classificação do país desde o início do processo de impeachment de Dilma Rousseff até fevereiro de 2018.

Tabela 1: Quedas do rating brasileiro entre dezembro de 2015 e fevereiro de 2018.

\begin{tabular}{|c|c|c|}
\hline Data & Agência & Ação \\
\hline 23 de fevereiro de 2018 & Fitch & Rebaixamento com perspectiva estável \\
\hline 11 de janeiro de 2018 & Standard \& Poor's & Rebaixamento com perspectiva estável \\
\hline 5 de maio de 2016 & Fitch & Rebaixamento com perspectiva negativa \\
\hline 24 de fevereiro de 2016 & Moody's & Rebaixamento com perspectiva negativa \\
\hline 17 de fevereiro de 2016 & Standard \& Poor's & Rebaixamento com perspectiva negativa \\
\hline 16 de dezembro de 2016 & Fitch & Rebaixamento com perspectiva negativa \\
\hline
\end{tabular}

Fonte: Dados do Tesouro Nacional (2018). Elaboração do autor

Como se pode observar, quatro desses rebaixamentos ocorreram ao longo do processo de impeachment, em um espaço de menos de um semestre. Outros três rebaixamentos, pelas três empresas, já haviam ocorrido poucos meses antes, entre agosto e outubro de 2015 - em contraste com os demais, que ocorreram apenas no período da primeira vitória de Lula da Silva em eleições presidenciais, conforme já apontado. Chama a atenção, por conseguinte, a frequência de rebaixamentos em um momento delicado do cenário político do país, sobretudo quando se sabe que as agências de classificação de risco têm como hábito atrasar downgrades em períodos eleitorais para, supostamente, não influenciar em seus

\footnotetext{
${ }^{14}$ Com efeito, em 2008, ao longo do segundo governo de Lula da Silva, o rating brasileiro obtém o grau de investimento - o que identificava o país como um bom pagador de sua dívida, não havendo, portanto, risco de calote. Tal condição seria, contudo, perdida, ao longo do governo de Dilma Rousseff, com o retorno ao grau especulativo.
} 
resultados (BUENFIL, 2017). O ativismo dessas agências durante o processo sugere, portanto, um desvio nesse comportamento.

Não obstante, o que se percebe a partir de suas declarações, ao longo desse período, é que o impeachment traria consequências negativas para o rating soberano do Brasil. Tal era a perspectiva da Moody's, que, na figura de um de seus principais analistas, Mauro Leos, alertou, ao final de 2015, que um eventual impeachment seria, na melhor das hipóteses, neutro para a avaliação do país ${ }^{15}$. Pouco antes do início do processo, a Fitch Ratings compartilhou de tal visão, declarando que "um eventual impeachment da presidente Dilma Rousseff seria um desdobramento negativo para a avaliação da nota do país" ${ }^{\prime 16}$. Entretanto, se antes da consolidação do impeachment os rebaixamentos vieram em massa, a realidade observada imediatamente após o ato não foi a esperada, como se pode observar na tabela a seguir, que retrata os primeiros ratings de cada agência posteriores à mudança presidencial.

Tabela 2: Primeiras avaliações do rating brasileiro após o impeachment.

\begin{tabular}{|c|c|c|}
\hline Data & Agência & Ação \\
\hline 15 de março de 2017 & Moody's & Confirmação da nota, com revisão da perspectiva para estável \\
\hline 9 de fevereiro de 2017 & Standard \& Poor's & Confirmação da nota \\
\hline 10 de novembro de 2016 & Fitch & Confirmação da nota \\
\hline
\end{tabular}

Fonte: Dados do Tesouro Nacional (2018). Elaboração do autor

Ainda que se possa argumentar que outros fatores incluídos na formulação do rating compensaram o impeachment, torna-se - diante da retórica construída antes e ao longo do processo - no mínimo inesperado que tal evento não tenha, afinal, produzido impactos negativos na avaliação do país. Por sinal, a única mudança ocorrida, como se pode perceber, foi positiva, com a revisão da

\footnotetext{
${ }^{15}$ Nessa entrevista à Reuters, em novembro de 2015, Leos já manifestava o desejo da Moody's e do mercado por ter Henrique Meirelles no Ministério da Fazenda, o que viria a se concretizar em menos de 1 mês, corroborando o viés pró-mercado do governo sucessor ao de Rousseff.

${ }^{16} \mathrm{Na}$ ocasião, conforme noticiado pela Folha de S. Paulo em outubro de 2015, o diretor da Fitch, Rafael Guedes, revelou que o ambiente político do país já havia sido o principal motivo do rebaixamento recebido anteriormente pelo país.
} 
perspectiva ${ }^{17}$ da Moody's de "negativa" - antes da saída oficial de Dilma Rousseff da presidência - para estável - após a oficialização de Michel Temer como presidente da república. Como sugerido por relatórios e declarações das agências, que serão melhor analisados a seguir, isso pode ser explicado pelas declaradas intenções do então novo presidente de implementar políticas de austeridade econômica e de promover mudanças, inclusive constitucionais, em sintonia com as demandas do mercado financeiro - assim como pelo apoio com que passava a contar no Congresso Nacional ${ }^{18}$.

Com efeito, o governo de Michel Temer se revelou seguidor dos preceitos do Consenso de Washington, aderindo a uma agenda econômica neoliberal. A convergência ideológica com as agências de classificação de risco passou, assim, a render ao governo elogios em seus relatórios frente ao seu comprometimento na promoção das reformas que, na opinião das agências, eram necessárias para melhorar a classificação do país. Nesse sentido, as primeiras sete avaliações recebidas pelo Brasil do governo Temer não vieram acompanhadas de piora no rating soberano - que se manteve, durante esse período, inalterado.

Porém, quando o governo Temer encontrou dificuldades para implementar uma dessas medidas, as agências de classificação de risco decidiram aumentar a pressão e evidenciar o viés político de sua atuação. Nesse contexto, o rating brasileiro volta a ser alterado em 11 de janeiro de 2018, quando a Standard \& Poor's decide rebaixar ainda mais a classificação do país. Na ocasião, o governo do presidente Temer encontrava dificuldades para obter, junto ao Congresso Nacional, os votos de que necessitava para a aprovação da reforma da previdência, então apresentada como condição para a recuperação das contas públicas. Diante dessa dificuldade, o relatório publicado pela agência, junto à divulgação do rebaixamento, justifica da seguinte maneira a queda do rating:

O enfraquecimento de nossa avaliação institucional do Brasil reflete o progresso mais lento do que o esperado e o menor suporte por parte da

\footnotetext{
${ }^{17}$ Segundo a Moody's (2018), em documento que resume seu sistema de ratings, as perspectivas são "opiniões relativas às prováveis direções dos ratings de um emissor no médio prazo, geralmente 18 meses", podendo ser positiva, negativa, estável ou em desenvolvimento.

${ }_{18} \mathrm{Em}$ maio de 2017, o presidente da Câmara dos Deputados, Rodrigo Maia, anunciava que "a agenda da Câmara, em sintonia com a do presidente Michel Temer, é a agenda do mercado", conforme noticiado pela Valor Econômico (2017).
} 
classe politica à implementação de legislação que possa corrigir deslizes fiscais estruturais de forma tempestiva. Os recentes desenvolvimentos políticos também prenunciam o risco de maior incerteza politica após as eleições nacionais que ocorrerão no final deste ano.

A estratégia de pressionar o governo através do rebaixamento da classificação do país veio, não obstante, repleta de elogios aos esforços do governo Temer para "gerar condições de crescimento e desempenho fiscal mais fortes nos próximos anos". Com efeito, o relatório da agência enumera os feitos do governo - que então ostentava um dos índices de popularidade mais baixos do mundo ${ }^{19}$ - como pontos positivos a serem destacados. A interrupção da boa trajetória com o rebaixamento do rating - e os impactos disso no balanço de pagamentos do país - parecia, assim, apenas um detalhe para um governo que, se altamente impopular entre os eleitores, gozava ainda de muito prestígio frente as agências, sobretudo diante de sua disposição para sacrificar políticas sociais em prol do ajuste fiscal:

[...] acreditamos que o governo Temer permaneça comprometido com a redução do déficit primário brasileiro. O governo tem avaliado e simplificado sistematicamente vários programas de gastos, quando possível (tais como empréstimos estudantis, subsídios para moradias - Minha Casa Minha Vida - e benefícios para deficientes), para gerar poupança orçamentária.

O relatório também menciona as incertezas causadas pelos escândalos de corrupção para os principais partidos políticos brasileiros. Nominalmente, contudo, apenas o ex-presidente Lula da Silva, do PT, é citado. Poucas linhas abaixo, a agência registra que "as instituições brasileiras têm se mantido sólidas em meio às investigações independentes e os subsequentes indiciamentos de práticas corruptas. Isso reflete a solidez institucional, em contraste com alguns dos pares do Brasil". Não há menção às controvérsias em torno do processo contra o expresidente $^{20}$, tampouco às investigações contra inúmeros membros do governo Temer, incluindo o próprio presidente ${ }^{21}$.

Não apenas a Standard \& Poors's, contudo, pressionava o governo pela continuação dos ajustes estruturais. No mesmo período, também a Moody's ameaçava rebaixar o rating brasileiro caso a reforma da previdência não fosse

\footnotetext{
${ }^{19} \mathrm{Em}$ janeiro de 2018, pesquisas do Datafolha revelaram uma aprovação ao governo de apenas $6 \%$. Meses antes, em outubro de 2017, o grupo de análise política Eurasia constatou que Temer era o presidente mais impopular do mundo, com aprovação de apenas $3 \%$.

${ }^{20}$ Em 23 de janeiro de 2018, por exemplo, o New York Times publicava artigo opinativo de Mark Weisbrot, que considerava que a democracia brasileira estaria indo rumo ao abismo com a condenação de Lula a partir de um processo repleto de irregularidades.

${ }^{21}$ Conforme noticiado pelo G1, em 20 de fevereiro de 2018, a polícia federal solicitava junto ao Supremo Tribunal Federal a prorrogação de um inquérito que apurava um suposto pagamento de propina à Michel Temer.
} 
aprovada - uma forma de atuar, em tom de chantagem ou ameaça, já observada por Ywata (2012). Em entrevista ao Estadão, em janeiro de 2018, a vice-presidente da agência, Samar Maziad, falou abertamente que o atraso na votação traria consequências negativas para o país num futuro próximo, uma vez que uma nova avaliação pela empresa aconteceria ainda no primeiro semestre do ano. De acordo com a executiva:

O progresso da agenda de reformas não aconteceu, o que era um componente muito importante para estabilizar o rating em Ba2. Agora vemos que as chances de aprovação da reforma da Previdência pioraram de forma significativa e num ano eleitoral é muito difícil ver uma reforma ampla ser aprovada. [...] O atraso e a não aprovação da reforma da Previdência seria um desdobramento negativo para o crédito do Brasil e continuaria a colocar pressão sobre o rating do País.

Entretanto, para a insatisfação das agências de classificação de risco, o governo Temer opta, em fevereiro de 2018, por suspender a tramitação da reforma da previdência no Congresso ${ }^{22}$. Diante desse acontecimento, a resposta imediata veio da Fitch Ratings, que, já no dia 23 do mesmo mês, rebaixou ainda mais o rating brasileiro. Em seu relatório do mesmo dia, em que explica as razões que geraram a piora na avaliação, a agência deixa claro que a "decisão do governo de não colocar em votação a reforma da previdência é um importante revés para a agenda reformista, que afeta a confiança da trajetória das finanças no médio prazo". O Ministério da Fazenda, diante da punição recebida pelo país, reafirmou, em nota, o compromisso do governo em seguir com a agenda reformista, conforme noticiado pela Folha de S. Paulo poucas horas após o relatório da Fitch vir a público.

Ao apresentar a reforma da previdência como um critério técnico e de indiscutível necessidade para a melhoria da situação fiscal do país e de seu rating soberano, as agências de classificação de risco fazem uso do artifício denunciado por Paudyn (2014), no sentido de colocá-las acima do debate político, ignorando seus impactos no âmbito doméstico. Assim, diante de tais ameaças, que nitidamente condicionam, no contexto apresentado, o rating brasileiro à essa reforma, convém elucidar alguns pontos que revelam o caráter ideológico dessas

\footnotetext{
${ }^{22}$ Conforme anunciado pelo Estadão, em 19 de fevereiro de 2018, essa desistência ocorre na esteira da intervenção federal na segurança pública do estado do Rio de Janeiro, o que inviabiliza qualquer emenda constitucional ao longo da vigência desse evento, que dura até o final do ano em que foi decretado.
} 
manifestações: i) outras alternativas que pudessem impactar positivamente nas contas públicas, em lugar da dita reforma, nem sequer vêm sendo cogitadas pelas agências, que pressionam para que essa medida, em especial, se consolide o quanto antes ${ }^{23}$; ii) o rombo na previdência e a necessidade da reforma são tratados como fatos incontestáveis, enquanto, na realidade, é um tema controverso e que vem suscitando debates entre especialistas ${ }^{24}$; iii) a reforma da previdência - ao menos no período de tais declarações - vinha sendo amplamente rejeitada pela população $0^{25}$; iv) em conformidade com a metodologia apresentada por essas empresas, a reforma da previdência não deveria ter o poder de, sozinha, movimentar o rating do país. Tal situação só seria viável em um cenário em que todos os outros elementos levados em conta no cálculo do rating se mantivessem inalterados, de modo a não haver qualquer tipo de compensação, o que, dado seu objeto de avaliação - o próprio país -, é pouco factível.

Como se torna claro a partir dos eventos analisados, a atuação das agências de rating vai muito além da mera classificação de risco do país - o que por si só já seria um mecanismo de interferência no jogo político nacional, dadas as consequências a ela inerentes. Ao se manifestarem constantemente, através da mídia ou de seus relatórios, essas agências são capazes de pressionar e constranger governos a adotarem as políticas por elas consideradas adequadas, influenciando direta e explicitamente escolhas que deveriam estar abertas ao debate popular e democrático. Desse modo, dada a roupagem científica e técnica com que a necessidade de uma reforma da previdência, por exemplo, é apresentada, promove-se sua blindagem do debate político, uma vez que, supostamente, trata-se de uma medida sine qua non para a recuperação da economia nacional. Como o

\footnotetext{
${ }^{23}$ Outras alternativas viáveis que melhorariam a arrecadação pública - mas que são ignoradas pelas agências de rating - poderiam ser, por exemplo, a implementação de uma estrutura tributária progressiva, o estabelecimento de impostos sobre grandes fortunas, heranças e dividendos, além do desenvolvimento de mecanismos que melhor combatessem a evasão de divisas (DOWBOR, 2017; PIKETTY, 2013).

${ }^{24}$ Pochmann, Moraes, Assis e Belluzzo (2017), por exemplo, contestam a necessidade da reforma da previdência proposta pelo governo Temer. Segundo esses autores, quando da manifestação do Banco Mundial em apoio à dita reforma, estávamos "diante de mais uma explícita manipulação ideológica para empurrar goela abaixo da sociedade brasileira a reforma previdenciária imposta pelo governo Temer, e cuja consequência seria ferir de morte, mais do que já se feriu, a dinâmica da economia."

${ }^{25}$ Em maio de 2017, pesquisa do Datafolha demonstrou que $70 \%$ da população brasileira era contra a reforma da previdência, conforme a Valor Econômico (2017). Em dezembro do mesmo ano, nova pesquisa, feita pela MindMiners, constatou uma rejeição de $69 \%$.
} 
objetivo dessa atuação é, ao final e ao cabo, que os governantes se vejam sem alternativa que não seja a implementação da medida propagada, independentemente desta gozar ou não de apoio da população, o sistema democrático do país se arrisca a sucumbir às pressões desses atores do sistema financeiro.

Ademais, como não há regularidade no timing de divulgação das avaliações, o excesso de manifestações das agências de classificação de risco ao longo do processo de impeachment de Dilma Rousseff também se torna problemático, dada a já comentada pré-disposição que as agências apresentam para discriminar governos de esquerda. Uma vez que seu substituto, Michel Temer, não só se mostrava propenso a adotar uma agenda neoliberal, mas também viria a compor seu governo com partidos de direita - derrotados nas eleições presidenciais -, as agências de classificação de risco teriam um estímulo a mais a para participar do processo mais ativamente, conforme ocorreu.

Por conseguinte, a capacidade de influência das agências de rating nas democracias nacionais não se limita ao poder que a função informacional que desempenham na globalização financeira naturalmente já Ihes permitiria desfrutar. $O$ processo democrático se encontra constantemente pressionado por esses atores externos, que se apresentam como entidades imparciais e apolíticas, podendo influenciar, assim, não apenas a situação de um balanço de pagamentos, mas também de eleições e de demais processos políticos na trajetória de um país. A realidade brasileira ao longo do século $\mathrm{XXI}$, e em especial durante e após o impeachment de Dilma Rousseff, desponta, finalmente, como representativa desses aspectos acerca da atuação das agências de classificação de risco.

\section{Conclusão}

O conjunto de processos que se convenciona chamar de globalização financeira pode impor hoje restrições à ação dos governos nacionais, de modo que estes se vejam constrangidos a aderir à agenda do mercado financeiro. Um dos canais que materializam essas pressões são as agências de classificação de risco, que informam ao mercado acerca dos riscos de seus investimentos por meio da 
atribuição de notas a potenciais tomadores de empréstimo. Não obstante, conforme demonstrado pela análise desenvolvida neste artigo, essas empresas podem fazer uso dessa prerrogativa para atuar politicamente nos países por elas avaliados, pressionando governos para que adotem as políticas que sejam, em sua visão, mais convenientes aos interesses do mercado financeiro - e que, supostamente, viabilizariam melhores avaliações.

Isso não significa, contudo, que as agências de rating sempre ajam dessa maneira nem que atuem ideologicamente de forma consciente ou, ainda, em conluio com outros atores no sistema financeiro internacional - hipóteses estas que poderiam ser trabalhadas em outras pesquisas. Com efeito, dadas as limitações metodológicas deste trabalho, o que se pode confirmar é tão somente que a possibilidade de que exerçam tal influência sobre os Estados é real. Neste artigo, a materialização de tal possibilidade é demonstrada pela análise do caso do Brasil, que, nos exemplos apresentados, sofreu reiterados constrangimentos nesse sentido - provenientes tanto das movimentações de seu rating soberano quanto de relatórios pretensamente técnicos divulgados pelas agências ou, ainda, de ameaças e críticas por elas explicitadas em canais de mídia.

É diante da observação dessa realidade que as agências de classificação de risco podem ser melhor problematizadas como um dos agentes que incidem sobre governança democrática em meio ao contexto de globalização financeira. Operando dentro de uma estrutura financeira que Ihes atribui um caráter neutro e técnico, os impactos promovidos por esses atores no jogo democrático podem acabar por não receber uma atenção condizente com a dimensão das consequências de suas ações. Como apresentado, isso pode fazê-los incorrer em ingerências em temas relativos à condução da política e economia nacionais, de modo a lesar processos democráticos internos aos Estados. Nesse sentido, esta pesquisa buscou contribuir com um maior esclarecimento acerca desses aspectos concernentes à atuação das agências de rating, o que, diante do analisado, constitui uma das demandas e necessidades contemporâneas para o aperfeiçoamento da democracia tanto a nível nacional quanto global. 


\section{Referências}

BARTA, Zsófia; JOHNSTON, Alison. Rating politics? Partisan discrimination in credit ratings in developed economies. Comparative Political Studies, p. 1-34, 2017.

BELLUZZO, Luiz G. Bolsonaro, o liberalismo político e a democracia. Disponível em: $<$ https://www.cartacapital.com.br/revista/991/bolsonaro-o-liberalismo-economico-e-ademocracia $>$ Acessado em 22 de fevereiro de 2018.

BLOCK, Steven; VAALER, Paul M. The price of democracy: Sovereign risk ratings, bond spreads and political business cycles in developing countries, Journal of International Money and Finance, v. 23, p. 917-946, 2004.

BOLTON, Patrick; FREIXAS, Xavier; SHAPIRO, Joel. The credit ratings game. Disponível $<$ https://www0.gsb.columbia.edu/faculty/pbolton/papers/CreditratingsJoF.pdf> Acessado em 19 de dezembro de 2017.

BRASIL, Classificação de risco da República Soberana do. Tesouro Nacional. Disponível em: <http://www.tesouro.gov.br/en/classificacao-de-risco > Acessado em 23 de fevereiro de 2018.

BUENFIL, Welmar E. R. Essays on the political economy of subnational public finances. Tese de Doutorado em Filosofia, California Institute of Technology, 2017.

CAMPELLO, Daniela. The politics of market discipline in Latin America: globalization and democracy. Cambridge University Press, 2015.

CARVALHO, Fernando C. de. Mudanças no papel e nas estratégias do FMI e perspectivas para países emergentes. In: FERRARI FILHO, Fernando; DE PAULA, Luiz F. (orgs.). Globalização financeira: ensaios de macroeconomia aberta. Editora Vozes, 2004.

BRASIL, Fitch rebaixa nota de crédito do. Folha de S. Paulo, 23 fev. 2018. Disponível em: <https://www1.folha.uol.com.br/mercado/2018/02/fitch-rebaixa-notade-credito-do-brasil.shtml> Acessado em 23 de fevereiro de 2018.

CHESNAIS, François. A globalização e o curso do capitalismo de fim de século, Economia e Sociedade, v. 5, p. 1-30, 1995.

. A mundialização do capital. São Paulo: Xamã, 1996. 
A proeminência da finança no seio do "capital em geral", o capital fictício e o movimento contemporâneo de mundialização do capital. In: BRUNHOFF, Suzanne de et al. (orgs.). A finança capitalista. São Paulo: Alameda Casa Editorial, 2010.

DATAFOLHA, Governo Temer tem a aprovação de $6 \%$ e reprovação de $70 \%$, diz. G1, 31 jan. 2018. Disponível em: <https://g1.globo.com/politica/noticia/governotemer-tem-aprovacao-de-6-e-reprovacao-de-70-diz-datafolha.ghtml> Acessado em 12 de fevereiro de 2018.

DOWBOR, Ladislau. A era do capital improdutivo: a nova arquitetura do poder, sob dominação financeira, sequestro da democracia e destruição do planeta. São Paulo: Outras Palavras \& Autonomia Literária, 2017.

EICHENGREEN, Barry. A globalização do capital: uma história do sistema monetário internacional. Editora 34, 2000.

EVANS, Peter. Constructing the 21st century Developmental State: Potentialities and Pitfalls. In: EDIGHEJI, Omano (org.). Constructing a Democratic Developmental State in South Africa: Potentials and Challenges. Capetown: HSRC Press, 2010.

FAZENDA, Decisão da Fitch é extemporânea e equivocada, diz BC e. Folha de $S$. Paulo, $212002 . \quad$ out. Disponível em: <http://www1.folha.uol.com.br/folha/dinheiro/ult91u57539.shtml> Acessado em 12 de fevereiro de 2018.

FITCH, Impeachment teria efeito negativo sobre rating do Brasil diz. Folha de S. Paulo, 15 out. $2015 . \quad$ Disponível em: <http://www1.folha.uol.com.br/mercado/2015/10/1694340-impeachment-teria-efeitonegativo-sobre-nota-de-risco-do-pais-diz-fitch.shtml> Acessado em 1 de fevereiro de 2018.

IOANNOU, Stefanos. The political economy of credit rating agencies: the case of sovereign ratings. Tese de Doutorado em Filosofia, The University of Leeds, 2016.

KUNDU, Amitabh. Politics and economics of credit rating. Economic and Political Weekly, v. 36, n. 4, p. 293-295, 2001.

KONINGS, Martijn; PANITCH, Leo. The Politics of Imperial Finance. In: PANITCH, Leo; KONINGS, Martijn (orgs.). American Empire and Political Economy of Global Finance. Palgrave Macmillan, 2009.

LE GALÈS, Patrick. Performance measurement as a policy instrument. Centre D'Etudes Europeenes, SciencesPo, 2016. Disponível em: $<$ http://www.sciencespo.fr/centre-etudes-europeennes/sites/sciencespo.fr.centreetudes- 
europeennes/files/1606\%20Le\%20Gales\%20Performance\%20Measurement.pdf> Acessado em 23 de janeiro de 2018.

LEKS, Luten. Credit rating agencies: do the notorious big two influence domestic austerity policy? Dissertação de Mestrado em Administração Pública, Universiteit Leiden, 2016.

LIMA, Maria L. L. M. P. L. Instabilidade e criatividade nos mercados financeiros internacionais: condições de inserção dos países do grupo da América Latina. São Paulo: Editora Bienal, 1997.

MATHIS, Jérôme; MCANDREWS, James; ROCHET, Jean-Charles. Rating the raters: are reputational concerns powerful enough to discipline rating agencies? Journal of Monetary Economics, v. 56, p. 657-674, 2009.

MOODY'S, 'Chances de reformar previdência pioraram', diz executiva da. Estadão, 20 jan. 2018.2 Disponível em: $<$ http://economia.estadao.com.br/noticias/geral,chances-de-reformar-previdenciapioraram-diz-executiva-da-moodys,70002157961> Acessado em 10 de fevereiro de 2018.

MOODY'S, Rousseff impeachment would be neutral "at best" for Brazil's rating. Reuters, 18 nov. 2015. Disponível em: <https://www.reuters.com/article/brazil-ratingmoodys/rousseff-impeachment-would-be-neutral-at-best-for-brazils-rating-moodysidUSL8N13D2MC20151118> Acessado em 23 de janeiro de 2018.

MOODY'S, Sistema de ratings da. Moody's. Disponível em: $<$ https://www.moodys.com/sites/products/ProductAttachments/sistemaderatingmoody s.pdf> Acessado em 20 de fevereiro de 2018.

MOSLEY, Layna. Global capital and national governments. Cambridge University Press, 2003.

PARTNOY, Frank. How and why credit rating agencies are not like other gatekeepers. San Diego Legal Studies, p. 7-46, 2006. Disponível em: $<$ http://lamfin.arizona.edu/fixi/creditmod/Portnoy.pdf> Acessado em 15 de dezembro de 2017.

PAUDYN, Bartholomew. Credit ratings and sovereign debt: the political economy of creditworthiness through risk and uncertainty. Palgrave Macmillan, 2014.

PESQUISA, Temer é o presidente mais impopular do mundo, diz. Huffpost, 26 out. 2017. Disponível em: <http://www.huffpostbrasil.com/2017/10/26/temer-e-o- 
presidente-mais-impopular-do-mundo-diz-pesquisa a 23256673/> Acessado em 22 de janeiro de 2018.

PIKETTY, Thomas. O Capital no século XXI. Rio de Janeiro: Editora Intrínseca, 2013.

POCHMANN, Marcio; MORAES, Reginaldo C., ASSIS, J. Carlos de; BELLUZZO, Luiz G. A reforma previdenciária querida do Banco Mundial. Disponível em: $<$ https://drive.google.com/file/d/10Hult9Hhm5ef3uBqWfo67P4thKTn9RZy/view> Acessado em 18 de fevereiro de 2018.

PREVIDÊNCIA, Após 14 meses, Temer desiste da. Estadão, 19 fev. 2018. Disponível em: <http://economia.estadao.com.br/noticias/geral,apos-fracassoprevidencia,70002195570> Acessado em 23 de fevereiro de 2018.

PREVIDÊNCIA, Pesquisa mostra que $69 \%$ são contra atual reforma da. Valor Econômico, 1 dez. 2017.2 Disponível em: $<$ http://www.valor.com.br/brasil/5214739/pesquisa-mostra-que-69-sao-contra-atualreforma-da-previdencia> Acessado em 5 de janeiro de 2018.

PREVIDÊNCIA, Pesquisa constata que $85 \%$ dos brasileiros são contra reforma da. Rede Brasil Atual, 14 nov. 2017. Disponível em: $<$ http://www.redebrasilatual.com.br/politica/2017/11/pesquisa-constata-que-85-dosbrasileiros-sao-contra-reforma-da-previdencia> Acessado em 25 de janeiro de 2018.

RATINGS, S\&P Global. Ratings de crédito soberano de longo prazo do Brasil rebaixados para 'BB-' na escala global por menor tempestividade e eficácia na elaboração de políticas; perspectiva estável. Comunicado à imprensa, 11 jan. 2018.

RODRIK, Dani. The globalization paradox: why global markets, states and democracy can't coexist. Oxford University Press, 2011.

SEN, Amartya. Desenvolvimento como liberdade. Companhia de bolso, 2000.

SINCLAIR, Timothy J. The new masters of capital: american bond rating agencies and the politics of creditworthiness. Cornell University Press, 2005.

SOUDIS, Dimitrious. Credit rating agencies and the IPE: not as influential as thought? Review of International Political Economy, v. 22, n. 4, p. 813-837, 2015.

STRANGE, Susan. States and Markets. Continuum, 1994.

The retreat of the state: the diffusion of power in the world economy. Cambridge University Press, 1996. 
STREECK, Wolfgang. As crises do capitalismo democrático. Novos Estudos, v. 92, 2012.

TEMER, PF pede prorrogação de inquérito que investiga. G1, 20, fev. 2018. Disponível em: <https://g1.globo.com/politica/noticia/pf-pede-prorrogacao-deinquerito-que-investiga-temer.ghtml> Acessado em 23 de fevereiro de 2018.

VAALER, Paul. M.; SCHRAGE, Burkhard; N., \& BLOCK, Steven A. Elections, opportunism, partisanship and sovereign ratings in developing countries, Review of Development Economics, v. 10, p. 154-170, 2006.

WEISBROT, Mark. Brazil's democracy pushed into the abyss. The New York Times. 23 jan. 2018. Disponível em <https://www.nytimes.com/2018/01/23/opinion/brazillula-democracy-corruption.html> Acessado em 25 de janeiro de 2018.

YWATA, Ricardo K. Ordem Mundial e Agências de Rating: o Brasil e as agências na era global (1996-2010). São Paulo: Editora Senac, 2012.

Recebido em: 02/03/2018.

Aprovado em: 11/06/2018. 